\title{
Aspects of Understanding Government's Public Institutions Behavior Necessary to Design Reforms
}

\author{
Stefan Imre ${ }^{1}$
}

\begin{abstract}
This paper presents some aspects found by the author in his research in field of government public institutions behavior. The author started some years ago to research the modality how should prepare a conceptual transfer of management from the companies practice to government public institutions and to implement them for enhance quality of their results. The main concept of the theoretical research is based on some well-known theoretical remarks. One of this shows that the public institutions are similar entities as companies. Eventually they have higher complexity. Following this logic, the public institutions should be led by management instead public administration. Considering public management and the new public management only some attempts without solving the main problems, the author consider that implementing procedural efficiency oriented management to the government public institution is equivalent with an important changes induced by outside.

Preparing the conceptual transfer, for the first period of research was necessary to understand government's public institution behavior. For this purpose the relational frame was the business organization. In this respect the research compares organizational behavior of companies and public institutions and their reaction to important changes. For understand similarities and differences it was necessary to discover theoretical standpoints regarding companies reaction to important changes induced by outside and main determinants from the organizational sciences literature. In the similar way was studied the public institution reaction and determinants of this to important changes, theoretically through documentary analyses of the literature of public administration.

The benchmarking between the reactions of the mentioned two entities discovered different behaviors and the main determinants of the reactions
\end{abstract}

\footnotetext{
1 West University of Timisoara, Doctoral School of Management. E-mail: stefan.imre@yahoo.com
} 
of them to a new form of leading system by management, including modern instruments as knowledge management.

The paper conclusions sustain that implementation of modern management systems to government's public institutions should deal with a different behavior used to know at companies. In this respect, the paper highlights different aspects between companies and public institutions behavior admitting similarities on organizational structure and internal procedures.

Keywords:

JEL Classification: public institution, organizational behavior, change, strategic availability, management.

H1, MOO

\section{Introduction}

The paper argues opportunity of research topic in the general context of the proposed reforms of state structures after the economic crisis started in 2008. Paper notes that institutional reforms in executive practice reducing government spending by reducing administrative capacities are not the best solutions. Reducing human labor employed in the central administration, which means reducing creative intelligence and lack of specific alternatives for maintaining or increasing the quality of the results of activities of these government entities, according to this paper may not enforce viable and sustainable progress.

In related issues, this paper offers important information about government's public institution behavior to understand future sense of actions. Taking in account the findings of this paper should be designed solutions to increase organizational performance in central government entity that is acting in specific tasks managing a portfolio of government. Policies and strategies developed by a better performing entity contribute directly to the competitiveness of the nation. In the same way good governance is seen as results of institution's activities noting quality of products and services provided to interested parties but it depends on capacity and capability of government institutions. Research in organizational competitiveness phenomenon discovered less known factors, which hide without sufficient motivation and adequate organization several inactive latent organizational forces.

Understanding internal forces and behavior of government public institution to changes induced by outside should help to design strategies for implement management instruments known at companies. In this activity the conceptual transfer of management systems model to government public institution has to deal with some other forces as known at the companies. But in the paper's opinion implementing procedures 
effectiveness and mobilizing latent organizational forces the results should be similar as in case of companies, namely better quality of products and services.

These considerations arising from the concept which deals with competitiveness as a phenomenon due to a complex management regardless of the nature of the entity where practical, business organization or public institution. The proposed based on general knowledge of allegations that the "public administration is not a science in itself " (Simon, H. 1950) and that "(state or public) institutions as entities do not differ from business organization, possibly they are more complex". This logic is reinforced by the statement that persists during the genesis of public administration, namely that "public administration should be separated from politics and based on management "(Woodrow, W. 1887).

In this sense, the paper presents the results of a multidisciplinary research including findings of organizational theories, public management and public administration, paper complies correspondence principle, although the proposed approach is innovative.

Comparative analysis of the behavior identified on organizational level at companies and public institutions regarding major changes induced revealed different situations due to lack of organizational culture's forces in public institutions. On one hand, at companies the management and leaders of changes promote changes for enhance competitiveness, on the other hand, at the public institutions due to the attitude is negative of the political leaders of institutions to changes internal conditions the progress is sequentially and is not continue as in case of companies.

Literature of public administration consider that" important changes" in public institutions are taken by the political leaders as a kind of redistribution of power trying to maintain actually situation without design perspectives of development.

Political leader's position is similar regarding implementation in institution technocracy, knowledge and science. The main argument is that knowledge can mitigate such political will.

In this respect, preoccupations to reform states institutions will meet difficulties due to conditions determined by the internal environment of public institutions governed less by managerial concepts of its leaders and more by public law and path dependence. Historically changes are made at public institutions by outside at national level regulated by national agency for public institutions and the stochastic evolution has a so called "path dependence" maintaining neo weberian bureaucracy structure.

A real reform of state structure should target both determinants, on one hand to reduce path dependency by law but maintaining general frame of functioning, on the other hand to implement efficiency procedures by management and management instrument to enhance institution's capability. The both mean enlarge management efficiency and effectiveness using active management instrument implementation which target is to enhance individual competencies and organizational capabilities, to mobilize internal intangible capitals as knowledge at human capital level, informational capital and organizational capital. In this respect should be possible the growth of strategic availability of government's public institution for implementing sectorial strategy 
regarding the portfolio given by the government. Enhancing functionality performances of public institution and utilizing management skills and instrument for procedures efficiency for sure is possible to have better results according to achieve designed goals and objectives. Achieving better results the government's public institution has a direct contribution to enhance the nation's competitiveness.

In paper opinion the described way of thinking and acting should be the best reform of the state institutions.

\section{Comparative analyses results on companies and public institutions organizational behavior}

The documentary review of the literature of business organization management revealed after examining the internal mechanisms of the organization that the availability to change, thus changing strategy of company is primarily responsible organizational culture formed over the years, and leadership (Schein, E. 2010). An important role in the formation of this behavior has knowledge management processes related to the implementation of knowledge in the organization by management, namely, knowledge contribution to increasing individual skills and increase organizational capability which determines the strategic readiness of the organization (Kaplan, Norton, 2004).

Unlike competitive business organization that integrates knowledge of the internal processes and organizational culture in order to increase performances, the analysis of the literature of public administration found that public administration remains indebted to recognition knowledge as a force of production and the main endogenous source of increase institution performance. Public administration theories support knowledge integration partially to public institution, only by increasing professional knowledge of civil servants. Technocratic solutions for public administration as use of knowledge, science in policy-making processes are considered approaches reducing the essence of representative democracy.

The analysis of presence of organizational culture in the public institution, which could be modeled by assessing knowledge management, the research found that theories of public administration support professional culture and less organizational culture. In this respect, there are no known papers in the field of public administration literature supporting the formation of creative institution's culture through knowledge.

In line with those presented by E. Schein (2010), Polanyi M. (1966), Nonaka, etc. (1995), Korgh G. (2000), the paper argues that tacit cultural values assumed collectively, implicit reference to the knowledge and assimilation of new knowledge, is the true force that directly influence innovation and productivity. The tacit values assumed operate without people awareness. Understanding how they operate, helps us to understand and perceive the whole image and the relationship between the components of culture, respectively, helps to explain social or organizational experiences. 
As such, in consensus with specialized researchers that the intelligence created in organization is dependent on organizational culture (Schein E. 2010, Schwaninger M. 2006). In conclusion, the inter-connection between knowledge - organizational culture strategic readiness is inseparable.

Knowledge was recognized as "productive force" alongside the traditional theories (Drucker, P. 1993; Bernhardt, D. 2003), or as the "most important power quality and power shift key" (Toffler 1990). It has become the resource base and sustainable innovation and increase competitiveness as theories supported by Peter Senge, Joseph Schumpeter, Edgar Schein, Jay Liebowitz, Ikujiro Nonaka, Hirotaka Takeuchi, Georg von Korgh, Michael Porter, Gary Hammel, Stephan Garelli, Klaus Schwab.

Literature, based on empirical analysis, finds as effects of integration of knowledge in the business organization ensuring flexibility and adaptability to the competitive conditions of the market. It defines the essence of strategic availability of the organization, providing functional competitiveness of the organization (Kaplan \& Norton, 2004; Liebowitz, J. 2010). In contrast, at public institution, lack of managerial concerns in knowledge integration decreases the formation of organizational culture, and strategic availability. In a nutshell, the lack of orientation of public administration to mobilize latent forces, involuntary influences institution behavior and reduce the acceptance of change.

\section{Public institutions administration specifics}

Government's public institutions activities are subject to double subordination, namely, legislation of public administration (Public Management) and the incumbent integration of political tasks on the organization of the government program. Power bureaucratic procedures maintain and develop public services in the context of public law and political leadership pressed to obtain objectives. According to Bernhardt D. (2003), "all differences between private and public management activities, objectives and evaluation of performance, however, differ relatively little". In other words, good governance is recognized by results like a good business management to the organization. However, the management of public institutions and management of business organization make the difference between their performances. Competitiveness is a concept that relates to management of business organization is charged with functional competitiveness of the organization and competitive results. At the head of the public management does not know the concept of competitiveness unequivocally content.

The logic presented above, public management differs from business organization management procedures, structures and behaviour (elements of organizational culture), both in the operational management and strategic management (targets, long-term goals). On the other hand, we find differences in the objectives set by management to stakeholders. Public management literature emphasizes the priority given to driving 
relationship of public management with politics and policy, satisfaction of stakeholders (especially in the political sphere), according democratic forms of society participation in decision making and policy formation, the problem of legitimacy. In terms of legality and legitimacy, strategies and objectives of government institutions are approved by the representative of political power (minister), in his capacity as responsible member of the Government and manager of portfolio.

The literature of public administration does not address the subject of public institution adaptability to external conditions of operation, considering that conditions are governed by the Agency public institutions. It also does not discuss the power of organizational culture as a central element forming attitudes that determine the positioning its members to knowledge integration to enhance institution's capabilities.

Public administration theory criticizes some managerial independence of the public management, considering that this diminishes the political decision-making power and contrary to the principle of representative democracy in whose name the political management appointed at "public institution does not meet democratic legitimacy" (Lynn, L. 2004).

Compared to business organization, public institutions strategy developed by civil servants depends on the consent and approval of the representative of political power appointed to lead the institution. The public institution is little affected by the changing external environment, the macro economic uncertainties. Conditioned reflex of employees to external turbulence is not high positioning public institution's policy towards them. Response time and the strategy adopted to manage economic sector for portfolio given by government are the subjects of dispute between political officials and civil servants, as bureaucratic power and political power.

In conclusion, formulating strategic goals, their approval through the eyes of the public politics and positioning of external environmental challenges clearly differentiates the reaction of the two entities, business organization and public institution.

The analysis of the literature of public administration, concludes that the main difficulties in differences (specific legislation, processes and organizational structure, decision making, relationships between public management and political management reforming public institution by transferring new conceptual approach to how to lead the public institution by complex management known at the business organization are due to: essential functioning and policies); Inertia of public bureaucracy described by path dependence and dependence on specific regulation; Lack of organizational culture formation leaders, facilitators creative intelligence; theoretical and practical concepts formulated by the political power opposing redistribution of power over the management which include technocracy, knowledge, sciences. 


\section{Public management specifics}

The most important transformation of the public administration is considered introducing elements of management of business organizations in public management. It means that public institution system can assimilate management methods and processes similar to those in the business organization. Articles discusses the introduction of management to the public institution and the importance of profession training of public manager for administering public institution modeled on corporate management issues. Public management followed by the new public management, pays more attention to entrepreneurial management performance and results measurement, without according him the status of leading initiator of exchange, thus leading knowledge integration. The manager has gained public recognition after conversion of public administration to public management "both in ideology and in state administration" (Lynn L. 1996).

Laurence Lynn (1996) shows that public managers get "a functional role from the perspective of politics, representing the organization in relation to third parties and is related philosophical tradition of scientific management (Madisonian and Taylorian), but also with political science and sociology". In this context, Kenneth Meier (1986) shows that the profession of public manager won place in the administration of the executive government and agencies, making the interface between political power and bureaucracy. The author believes that the role of head of the institution is to provide power for the organization. According to the present paper, obtaining prestige and importance of the institution is possible through enhance quality services developed to stakeholders, which involves human resources and other intangible values of the public institution.

Another interpretation on the role of public manager sustains that "public institution is to provide resources and autonomy to achieve public policy goals by using cohesive and co-opted members demonstrate expertise" (Behn R. 1991). This opinion is not worth the results of the public institution in winning resources necessary for the operation and grant public manager bargaining power requirements without providing technical argument.

Some authors in political science consider, however, the introduction of public management is a factor that redefines the organization's culture. According to Steven Kelman (1987) features define new public management culture of the profession and organization, where "analytical and quantitative justification replaces rational managerial model of Frederick Taylor, the trend of action, customer intimacy, autonomy (strategy) and entrepreneurship". Some similar ideas are found at Peters and Thomas (1982). In these circumstances, they consider it becomes possible stakeholder satisfaction.

According to the present paper, the government has not been applied rational model Taylor's leadership, because dominance public administration law's procedures regulated at national level the public administration and management logic does not belong management processes. Similarly, the profession of public management culture 
in a public institution with "one" public manager is impossibly to get profession cult because missing members in forming micro cultural interaction. Although this professional culture would form could not affect the position of the majority of employees to change their position in case of strategy changes or knowledge integration. In this respect, the mentioned culture elements does not work as real latent forces as in case of organizational culture formed at the business organization.

Theoretically, post bureaucratic paradigm considers valuable public argumentation and deliberation of public manager, creating a high mission and strategic planning implementation, commitment to quality, investing in human resources but not without political opinion (Barzelay M . 1992). Management of public institutions remains so between two related traditions, namely, political and administration.

Even so, this new public management in Europe is identified by the transformation of state structures in a neo Weberian form through the modernization of political power and public administration structure. Pollit (2005) found that neo Weberian state is conservative by supporting national character and government transformation. In general, the literature considers that neo Weberian state support less change in the structure of political power as such maintain capitalism, or even aggressive global capitalism, "the administrative elites are influenced to weaken the command and control system of bureaucracy". On the other hand, changes in administrative structures "contradict to the rebirth of democracy" postulated by Lynn (2008) for reasons of legitimacy.

In present paper opinion the need for real reforms are going to formulate policies by public with public for public and in the future to attempt policies without politic. This should be the real path orientation for public institution in the name of participative democracy. In a strategic thinking to start this way the reform of state structure should start with implementation of management to sure procedure efficiency and management of intangible capital of public institutions.

\section{Relation between public policies and knowledge and sciences}

Along the transformations undergone by the Weberian bureaucracy to new forms of public management, new public management and new governance dispute between technocracy and politicization is going on. Public administration became public management, where responsibility and decision performance (notions borrowed from business management theory) was implemented partially. In parallel with implementing technocracy elements on documents management, Hisschenmoller (1998) and Dunn (2010) found removal masses participation in the formation of decisions due to specialized technical policies. In this sense, the authors show the main reason for reducing the influence of rational-legal authority to elected officials. In this respect, according to the literature, problem solving public policy making should not be sought 
outside the institution, as in the best practices of private organization, but rather in thinking which is acting with the external environment. Technocracy increase the quality of public administration and somehow integrate some knowledge in activities, but this is viewed as a delimitation from the will of the masses.

According to Dunn (1998) scientific knowledge to practical knowledge is ignored, because of politicians, which often has no preparation or availability understanding of scientific documents. In specific cases, it can be seen positive cooperation between science, politics and participation policies, problems are solved by consensus. Such problems are related to environmental protection, which "translates into political science," (Dunn.W, Hisschenmoller, M. 1998). Scientific instruments for analysis were taken from the private sector management. The political analyzes have become important tools for informing power.

I present paper opinion maintaining such theories on political sciences represent the real barriers of thinking toward real reforms on state structures in some countries. Real progress in this field is seen at Nordic countries where are recorded several success regarding public institutions flexibility and procedures efficiency.

\section{The role of knowledge in change of public institution}

Based on the principles known at the business organization, the position of the public institution to changes has to be determined by the pseudo culture of the institution, but also on the ongoing leadership. In reality, public institution official leadership is taken by the appointed political power representative. Formation of an organizational culture is not possible due to lack of leadership in this regard, the lack of integration of knowledge. Internal institutional environment is the result of relationship between the bureaucratic power and political power, which is a timely equilibrium less as a legislation duration. Several changes at the public institution leading power at lack of preoccupation to enhance organizational culture power by knowledge integration make impossible formation of institutional culture. Relevant researches sustain in this activity necessary more than 14 years acting with professional instruments (Schein, E. 2010, Libowitz, J. 2006).

Change at the business organization is facilitated by the initiator of change, such in enhancing organization culture, assuming the position of leadership, esteemed for professional knowledge and dedicated designer (steward) to organization and its interests. The leader in public institutions could have the same role in implementing knowledge within the scope of business organization, but in the literature of public administration there is no presentation assumes this function.

Studied literature makes clear that politics is not happy on the organizational structure changes and on broadening the competencies of the public manager, such to create conditions in internal environment to creative intelligence, what require significant structural and procedural changes. Instead of these changes, politics suggests "to identify existing potential for improving the organization of the institution" (Lynn L. 
1996). The author believes that reducing public manager intellectual agenda, required to implement a policy framework and institutional potential given the intellectual and practical consequences are "unfortunate".

Accordingly, the final decision on changes, even more conceptual integration of complex management and the formation of organizational culture to create conditions to develop intelligence and knowledge integration belongs to political power. Exploring latent organizational force, such as knowledge and forming organizational culture should be a common target of public servants and political power to enhance public institution's performance, but this "contribution of civil servants and science is profoundly antidemocratic" in opinion of Fischer (1993). On the other hand, Heclo (1977) considers that the executive power represented by political officials going through the real test of governance art establishment if he changes it wants without losing bureaucratic services that it requires. In this context, constructive cooperation between political officials and civil servants is the only way to achieve the objectives, but it needs to be sustained from outside by academic level and public institution functioning law modification.

The present paper mentions more a theoretical position about relation between bureaucracy power and political power. Hierarchical organization of functional division of activities and employees in the professional category of civil servants, maintains bureaucratic power and "reduces administrative power of political leaders. Organizational system allows only bureaucratic staff adherence to the norms and values of the institution" (Guichard, J. 2008).

Present paper concludes that political theories presented do not sustain real reform by knowledge integration and mobilizing latent force of intangible capitals. In this respect is very clear that from their point of view is not important efficiency of functioning public institution by knowledge integration and mobilizing intangible capital. In the same way, political sciences do not sustain changes regarding flexibility of public institutions by knowledge integration to individual competencies and organizational capabilities which enhance organizational culture and strategic availability.

\section{Conclusions}

The final conclusion of the present paper regarding possibility stating efficient reforms at public institution notes that there are no sustain from political sciences at all. Public administration theory seems to be satisfied by dealing with new public management and has no objection regarding so called "reforms" on going by reducing public institution capacity.

A real reform proposed by present paper by complex management transfer concept and strategic intelligence system to public institution will meet several barriers in implementation. This barriers are different from those identified at the business organization regarding changes induced. 
First of all, paper sustain that availability of the inertial behavior to change induced outsight depends on its degree of readiness to accept "new" and "change", both of which are determined by the level of knowledge embedded in the organization.

This paper notes that inertia of organization is a significant barrier to change, such as the implementation of new strategies or new types of management. Research findings theoretical barriers in induced change at public institution shows that the major impediments due to political leadership behavior rather than pseudo elements of institutional culture. The main impediment lies in the attitude of the political power to knowledge, science and management by technocracy, which diminishes legitimate political power and redistribute power.

By present paper opinion the possibility of reducing transaction costs through cooperation between bureaucratic and political power should be important in common understanding how to envisage following changes. But that internal change initiative is insufficient and must have external initiative, especially from academics to persuade scientific solutions, as transform the public administration to performance oriented and procedures efficiency, and the same time to enhance the strategic availability mobilizing intangible capital. In this sense should enhance quality of results of the government's public institution and contribute to national competitiveness.

\section{References}

Barzeley M.1992, Breaking through bureaucracy, University of California Press, Minessota

Behn R. 1991, Leadership counts: lessons for public managers from the Massachusetts welfare, training, and employment program, Harvard University Press

Bernhardt D 2003, Competitive Intelligence. How to Acquire \&Use Strategic Intelligence and Counterintelligence, Financial Times Management, Prentice Hall

Dunn W. N. 2010, Analiza politicilor publice. O introducere, Polirom, Bucuresti

Dunn W.N, Hisschenmoller M 1998, The knowledge, power and participation in environment policy analysis, Transaction Publishers Publishing House

Drucker, F.P. 2010, The Essential Drucker, Editura Meteor Press, Bucuresti

Fisher, F 1993, Citizen Participation and the democratization of policy expertise. From theoretical inquiry to practical cases, Policy sciences 1993, vol26, pag165-187.

Guichard, J.P. 2008, Challenges of Economic Sciences in the 21th Century. Institute of Economic Sciences of Serbia

Heclo, H. 1977, A government of strategies: Executive Policies in Washington, Brookings Institution Press

Kaplan, S.R.; Norton, D.P. 2004, Measuring the Strategic Readiness of Intangible Assets, Harvard Business Review

Kelman, S. 1987, Making public policy: A hopeful view of American Government, Basic Books 
Von Korgh, G. 2000, Enabling Knowledge Creation: How to unlock the mystery of tacit knowledge and release the power of innovation, Oxford Reprints, Oxford University Press

Liebowitz, J. 2006, Strategic Intelligence: business intelligence, competitive intelligence and knowledge management, Auerbach Publications, Taylor and Francis Group

Lynn, L. 2004, Managementul public, ca artă, ştiinţă şi profesie,Asociatia Editoriala Noi, Chisinau

Lynn, L. 2008, What is a Neo Weberian State?, Reflections on a concept and its implications, Univ. Chicago, available on http://iss.fsv.cuni.cz/ISS-50-version1080227_TED1_Lynn_Whats_neoweberian_state.pdf, accessed in November 2014

Meier, K., Bohte, J. 1986, Politics and bureaucracy, Cengage Learning US

North, D. 1991, Institutions, Journal of Economic Perspectives. Vol 5. No1. Winter. Pages 97-112

Nonaka, I., Takeuchi, H. 1995, The Knowledge Creating Company: How Japanese companies create the dynamics of innovation, Oxford University Press

Pollitt, C. 2005, Performance management in practice. Journal of public administration research, 29 June 2005.

Porter, M. 1998, Versenystrategia, Akademia Kiado Publishing House

Schein, E. 2010, Organizational Culture and Leadership, John Wiley and Sons Publishing House

Schneider, A. and Ingram, H. 1990, Behavioural assumptions of policy tools. Journal of politics 52:2:10

Senge, P. 2012, The fifth discipline: the art and practice of the learning organization, Doubleday, New York

Simon, H. 1950, Public Administration, New York

Waldo, D. 1948, The Administrative State. New York, The Ronald Press Company. Accessed on https://archive.org/details/administrativest030066mbp

Woodrow, W. 1887, The Study of Administration. Political Science Quarterly, accessed on http://teachingamericanhistory.org/library/document/the-study-of administration/ 